\title{
A study to assess impact of teaching proper case history taking of the most common psychiatric disorder - Major Depressive Disorder (MDD) in Interns
}

\author{
Bhaveshkumar M. Lakdawala ${ }^{1}$, Parlin M. Dadhaniya ${ }^{2}$, Tanvi G. Kacha ${ }^{3}$ \\ ${ }^{1}$ Professor \& Head, Department of Psychiatry \\ ${ }^{2}$ Third Year Postgraduate Student \\ ${ }^{3}$ Second Year Postgraduate Student \\ AMC MET Medical College and Sheth L.G. General Hospital, Ahmedabad, Gujarat \\ Corresponding author: Parlin M. Dadhaniya \\ Email - parlin30dadhania@yahoo.in
}

\begin{abstract}
Background and Objectives: Psychiatry lectures \& clinical posting are the only learning experience of psychiatry for Medical Graduates. Only interns attend their compulsory psychiatry posting. The aim is to make Interns competent to elicit \& write proper history of MDD and able to describe different components of history taking, diagnostic criteria, to demonstrate communication skills.

Methods: It was a Prospective Interventional Study done in 45 Interns posted consecutively in Psychiatry. On Day1, Interns were asked to take and write history of MDD patient and evaluated on Checklist for history taking (10 components), SMCQ (15) and Mini-CEX. Then Interns were taught about MDD by CBL, SGL and Role Play. On Day 7, they were again evaluated on Mini-CEX. On term ending, they were again evaluated as per Day1. Feedback of Interns and faculties were taken. Appropriate Statistical Tests were used using SPSS Version 16.

Results: On Checklist for history taking of MDD apart from Negative History and Mental Status Examination, Interns' skills improved significantly. Mean score on SMCQ got doubled from $6 \pm 0.83$ to $12 \pm 0.83$. On Mini-CEX, apart from clinical judgement, counselling skills and overall clinical competence, Interns improved from unsatisfactory to superior level. Feedback was positive on most of the components of study but few were satisfied completely with their history writing \& communication skills and diagnosing ability. Faculties' perceptions were very encouraging.

Conclusion: Teaching of MDD case history taking was well taken \& perceived by interns. Knowledge about MDD \& competency to take history and identifying patients of MDD improved satisfactorily.
\end{abstract}

Keywords: Interns, history taking, MDD, psychiatry, mini-CEX.

(Paper received $-10^{\text {th }}$ November 2018, Peer review completed $-20^{\text {th }}$ November 2018)

(Accepted $-26^{\text {th }}$ November 2018)

\section{INTRODUCTION}

There has been an increasing demand to improve psychosocial skills of medical care among medical students. All medical students will not be psychiatrists. For those, psychiatry lectures and clinical posting are the only experience of psychiatric practice before they start to work as clinicians. For all doctors, Knowledge of psychiatry is important because prevalence of mental illness is 5 to $20 \%$ in general population 
and the most common is Major Depressive Disorder (MDD) [1-2]. It is so common that each doctor should know how to take history of MDD patient, what the diagnostic criteria are and how it can be treated. In severe cases, MDD patients can attempt and commit suicide. Around fifty (50\%) of patients with MDD attempt suicide and $15 \%$ of the patients die of suicide, still patients don't seek treatment from mental health professionals or any doctor just because of stigma attached to mental illness. There are about 6000 psychiatrists in India, i.e., $<0.5$ per $1,00,000$ population [3]. The ideal number required is 1 per $1,00,000$ population [4]. It has been found that $20 \%$ of new consultations to a primary care physician are for somatic symptoms for which no physical cause can be found [5]. Primary care physician often fail to recognize psychiatric disorders in patients with physical illness [6]. In medical and surgical wards, half of the psychiatric morbidities are not detected by doctors [7]. The training that the undergraduates and interns gets in their psychiatry posting will change this situation. Currently, medical undergraduate students have multiple lacunae in their knowledge of psychiatry with various myths, misconceptions and negative attitude [8].

Skills in communication and the ability to form empathy are fine-tuned while learning psychiatry and are essential qualities for a doctor. Encouraging positive mental health and counselling skills to reduce stress and cope with chronic physical health problems are necessary for all doctors to master. Also an increasing need for improved skills by medical graduates in the psychosocial aspects of medical care has been noted [9]. In the course of his or her professional life, a clinician will conduct between 1,00,000 and 2,00,000 patient interviews [10-11]. The medical interview is the most common task performed by physicians. Thus, for good reason, Engel and Morgan called it "the most powerful and sensitive and most versatile instrument available to the physician" [12]. Scientific discoveries and technological innovations of the last decades fundamentally changed diagnostics and treatment of diseases. Imaging studies and laboratory tests seem crucial for an accurate diagnosis, all the more in times of multidisciplinary treatments and overall availability of instrument-based examinations. However, neither scientific nor technological advances in medicine have changed the fact that a physician's core clinical skills are interpersonal [13-15]. Interview skills contribute significantly to problem detection, diagnostic accuracy, patient and physician satisfaction, patient adjustment to stress and illness, patient recall of information, patient adherence to therapy and patient health outcomes [16-20]. Accuracy of diagnoses and the establishment of a good physician-patient relationship depend on effective communication within the medical interview [21-22]. By the medical history, physicians garner $60-80 \%$ of the information that is relevant for a diagnosis [22-26] and the history alone can lead to the final diagnosis in $76 \%$ [22].

Encouraging positive mental health and counselling skills to reduce stress and cope with chronic physical health problems are necessary for all doctors to master [9]. It is a matter of concern that students are not clear of the psychiatrist's role in the multidisciplinary team and they think a medical background is not necessary to practice psychiatry [27-28]. Because knowledge and attitude of undergraduate toward mental health \& psychiatric disorder is of great importance as they are going to be involved in care of these patients directly or indirectly during their careers [29]. Studies in medical students found out opinion about Mental Illness have shown ignorance about psychiatry, psychiatric patients and their treatment [30].

Most of the literatures show negative attitude of the students toward psychiatry [31-33]. Emphasis on psychiatry during undergraduate training has been low. The MCI has recommended that all undergraduate students receive 2 weeks' clinical posting and 20 lectures in psychiatry in the fifth semester and assessment in the form of short notes in paper two of General Medicine [34]. From 2008, 2 weeks psychiatry posting is compulsory during internship. Formal teaching during internship is not feasible given the time constraints in most departments, but having a guideline about what the posting should achieve for the intern and the department is beneficial, it can go a long way to benefit students [35].

While planning for undergraduate teaching, we should consider that this essential training/learning experience not only provides knowledge and skills but makes psychiatry interesting and removes the stigma of being a psychiatrist and also toward psychiatry and its patients. The quality of the teaching, enthusiasm of the clinical teachers, the holistic approach and scientific basis of psychiatry are the parameters that influence the students' attitude toward psychiatry [36-37].

There are very few studies in which impact of teaching of psychiatry in medical undergraduates has been studied [33]. In psychiatry, the history taking and Mental Status Examination are the most important 
diagnostic tools to make an accurate diagnosis. History taking and communication skills programmes have become cornerstones in medical education over the past 30 years and are implemented in most US [15], Canadian [17], German [38] and UK [39] medical schools. National accreditations and expert panel consensus guidelines have stressed the importance of educational interventions addressing history taking [40-41].

The only essential quality that a teacher should have to teach psychiatry is interest in teaching. Everything else can be learnt. Greater faculty involvement in teaching and direct observation of medical trainees with actual patients are important for the assessment of clinical skills [42]. Application of skills in the areas of medical interviewing, physical examination, and counselling is required for the successful practice of medicine [43]. However, medical students report that they are rarely being observed during patient encounters; one main reason is a lack of faculty time [44]. The direct observation is mandatory for the reliable and valid assessment of interviewing and counselling skills [45-46].

Although traditionally lectures impart information and knowledge didactically, it is good to use role-play and to demonstrate skills while teaching communication skills. Other good teaching practices, e.g., asking questions, giving opportunities for the students to ask question, etc., should be paid attention to. Appropriate use of audio-visual aids remarkably improves the impact of the class [42].

For checking knowledge, Structured Multiple Choice Questions (SMCQs) are more reliable, because of the large number of items that can be easily tested and marked. These can be adapted to test knowledge as applied to problem solving or clinical reasoning [47].

For evaluation of skills, it is better to use more appropriate, structured, reliable, and valid methods of skill assessment such as OSCE, OSPE, Mini-CEX, and Objective Structured Long Examination Review (OSLER) [48].

The mini-Clinical Evaluation Exercise (Mini-CEX) is a method of the assessment of clinical skills including counselling skills and professionalism, developed by the American Board of Internal Medicine [49] and has been used in clerkships as a feedback tool [50]. After an evaluator observes a trainee's performance in a normal clinical encounter, trainee receives immediate feedback [51]. For each encounter, an examiner (attending) recorded the date, the complexity of the patient's problem on 3-point scale (low, moderate, and high), [52] the sex of the patient, the number of minutes spent in observing the encounter, and the number of minutes spent in giving feedback [53]. Using 9-point scale (in which 1-3 were "unsatisfactory," 4-6 were "satisfactory," and 7-9 were "above expected"), the examiner (attending) rated the student on interviewing, physical examination (mental status examination), professionalism, clinical judgment, counselling, organization and efficiency, and overall competence [52]. The emphasis on counselling included student's interaction with the patient professionally (introduced himself/herself, maintained good eye contact) and education (explained the rationale for test/treatment). After the interview, the examiner (attending) completed the rating form and provided feedback [54].

Psychological aspects of medical care give an additional opportunity for hospital psychiatry, and the internship offers interpersonal experiences of the clinical encounter and medical care [55]. Given this position, clerkship provides a great opportunity for exposure in patient communication.

Keeping this important aspect of history taking as an essential tool for any doctor, I decided to study this as my education project of Advance Course in Medical Education (ACME).

As specified by the Medical Council of India (MCI), Faculty Development Programs aim to improve the quality of medical education by training and sensitizing teachers about new concepts in teaching and assessment methods; develop knowledge and clinical skills required for performing the role of competent and effective teachers, administrators, researchers and mentors; assist clinicians to acquire competency in communication and behavioural skills and update knowledge using modern information and research methodology tools [56]. MCI, in 2014, started Advanced Courses in medical education with the aim to develop educational practitioners who can lead informative, instructional and educational changes in their institutions and thereby making the medical education responsive to the health needs of the society.

ACME is a one-year course approved by MCI and run only by MCI Nodal Centre. Faculty in medical college who had done Basic Course of Medical Education Technologies (MET) can only enrol for ACME. The purpose of the Basic Courses in MET is to provide the basic knowledge, skills and eventually change 
the attitude of the faculty in medical colleges, which the faculty can implement in their day-to-day practice in different areas of teaching and assessment (classroom, laboratory, clinical and field work) [57].

I did this course at MCI Nodal centre for faculty development at Smt. NHL Municipal Medical College, Ahmedabad, Gujarat. It had two contact sessions at MCI Nodal Centre, first for 5 days and second after 6 months for 3 days. After first contact session, each faculty had to make one research project and present poster of the same during second contact session. At the end of course, faculty had to submit complete project. In first six months, there were online discussion on 5 different topics namely CBME, Integrated teaching, faculty development, E-learning and Qualitative research. Faculties are divided in a group and each group had to moderate one allotted topic. Each topic was discussed for 1 month duration. In each topic, 5-7 threads are released online at 3-4 days interval by moderating group. In which each participant had to mail at least 2 mails during a week. Two expert faculties in each group give active guidance to participants and look after online activities. Each participant compulsorily had to moderate one thread and keep record keeping of one thread in a group allotted. Even senior batch also had to participate actively in this online activity until that batch's one year course is completely finished and approved by Nodal centre. In a second contact session, each faculty had to present a poster of his or her research project. After second contact session, again participants were divided in 5 groups. Now, new batch joined with our batch. In last six months, there were online discussion on other 5 different topics namely programmatic assessment, interactive teaching, giving and receiving feedback, professionalism and ethics and scientific paper writing $\&$ grant writing. Same procedure mentioned above for first six months are again done in these six months with different topics, groups and experts. At the end of all topic discussion, each faculty had to submit his or her complete project online for completion of course which would be approved by Nodal centre as per criteria and guidelines. So, ACME is a rigorous and meticulously planned course for faculty development. The aim of the study was to make Interns competent to take proper case history of the most common psychiatric disorder - Major Depressive Disorder (MDD). The objectives were to make sure that interns should be able to describe different components of psychiatric case history, the diagnostic criteria of Depression and should be able to demonstrate communication skills with patient while taking history of MDD along with being able to write history of patient of Depression

\section{METHODOLOGY}

It was a Prospective Interventional Study and was done in 45 Interns during their 15 days of compulsory posting in compulsory posting in Psychiatry Department in AMC- MET Medical College and Sheth L.G. Hospital, Ahmedabad as a part of education project of Advance Course in Medical Education (ACME).

\section{Inclusion Criteria:}

1. The Intern Doctor posted in the Department of Psychiatry for their compulsory rotating internship duties.

2. The particular intern doctor had to give consent after being explained in his/ her language of understanding, the entire study aims and design.

3. Age more than 18 years

4. Either gender

5. Able to understand Hindi/English/Gujarati

\section{Exclusion Criteria:}

1. Intern Doctors who were not posted in the Department of Psychiatry

2. Intern Doctors who did not give consent

\section{Pre-test (Day 1):}

- On day 1 of enrolment in Psychiatry Dept., Interns were asked to take case history of patient of MDD. and to write down the history taken.

- Interns were observed on Structured MCQs (SMCQ) and Mini-CEX while taking history and written history was evaluated on Checklist for history taking. 


\section{Midterm Evaluation (Day 7):}

- Interns were taught in detail about history taking method of MDD patients ( $\boldsymbol{T}-\boldsymbol{L}$ Method: CBL, small group lecture/discussion, audio-visual method, role play) and lectures were taken on MDD

- After 7 days, Interns were observed on Mini-CEX ( $2^{\text {nd }}$ time $)$ while taking history of MDD patient.

\section{Post-test (Day 15):}

- At the end of term, Interns were asked to take case history of patient of MDD and to write down the history taken.

- Interns were observed again on SMCQ and Mini-CEX ( $3^{\text {rd }}$ time) while taking history and written history was evaluated on Checklist for history taking ( $2^{\text {nd }}$ time) to see the change of skills and method of history taking of patient

- Feedback of Interns was taken by standardized Feedback form

- Qualitative feedback from both Interns and Faculties were taken

Data collection period was 2.5-3 months and the total study duration was 6 months. The total number of interns enrolled in the study were 45. Pre-test (Day 1), Day 7 and Post-test (Day 15) data were analysed using appropriate statistical tests using SPSS Version 16.0. Wilcoxon signed rank test was used to compare pre and post-test findings of checklist of history taking. Unpaired t-test was used to compare pre and posttest SMCQ score. Chi square test and Friedman test was used to compare Mini-CEX results. P value of < 0.05 was considered statistically significant.

\section{Instruments used}

- Socio-demographic profile sheet: It consists of a structured format to record certain variables regarding the intern doctor, such as age, gender, type of family, income of family, locality etc.

- Informed Consent Form: for participation in study

- The ABIM Mini-Clinical Evaluation Exercise for Trainees (Mini-CEX): is intended to facilitate formative assessment of core clinical skills. It can be used by faculty as a routine, seamless evaluation of trainees in any setting. The Mini-CEX is a 10- to 20-minute direct observation assessment or "snapshot" of a trainee-patient interaction. It is a questionnaire comprising of 7 questions which has feedback answers graded on a Likert Scale and 2 questions of evaluator's and trainee's satisfaction [53, 58-59].

- Check list for History Taking (Annexure IV): Is a check list comprising of 10 topics on which the components of the history taking can be assessed. This check list can be administered in a span of 10 minutes by assessing the history taken by the candidate.

- Structured Multiple-Choice Questions (SMCQ) (Annexure V): It is a questionnaire comprising of 15 questions with 4 options each. The questions are framed based on the DSM 5 diagnostic criterion of Major Depressive Disorder, its treatment and on basic history taking in Psychiatry. The questionnaire can be applied in about 10 minutes and is used to evaluate the candidate's knowledge on Psychiatric History taking and Major Depressive Disorder.

- Standardized Feedback Form for students (Annexure VI): Is a questionnaire comprising of 10 questions which has feedback answers graded on a Likert Scale. The questionnaire is aimed at understanding the student's point of view as far as the teaching in medical colleges is concerned. This can be administered in a span of 10 minutes. It comprises of knowing as to what would comprise a conducive and encouraging atmosphere for students to ask questions uninhibitedly and discuss topics and ideas frankly.

Socio-demographic Profile:

\section{RESULTS}

Total 45 Interns were enrolled in the study. Mean age of Interns was 22.38 years. Majority were from nuclear family and of urban background. 
Table 1: Socio-demographic details

\begin{tabular}{|cccc|}
\hline Variable & Variable & $\mathbf{N}=\mathbf{4 5}$ & $\%$ \\
\hline Sex & Male & 24 & 53.3 \\
\cline { 2 - 4 } & Female & 21 & 46.7 \\
\hline Age & Mean (SD) & $22.38( \pm 0.490)$ \\
& & \multicolumn{2}{|c|}{} \\
\hline Family & Nuclear & 34 & 75.6 \\
\cline { 2 - 4 } Type & Extended & 11 & 24.4 \\
\hline Locality & Urban & 40 & 88.9 \\
\cline { 2 - 4 } & Rural & 05 & 11.1 \\
\hline
\end{tabular}

\section{Checklist of History Taking:}

Figure 1: Checklist of History Taking

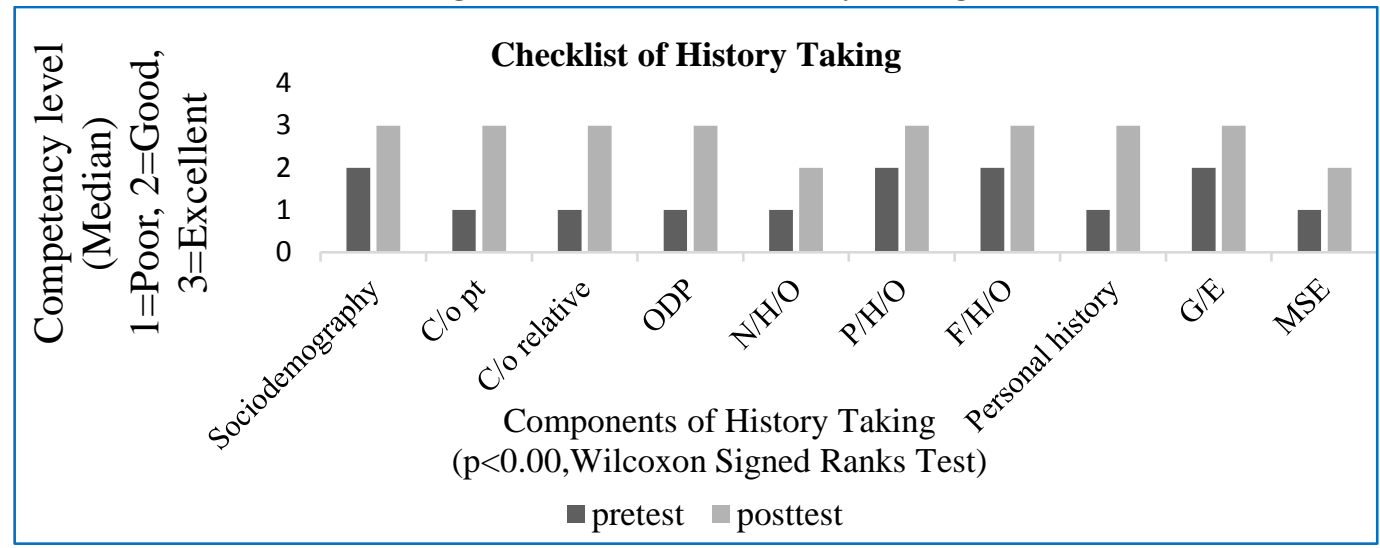

Table 2: Checklist of History Taking

\begin{tabular}{|ccccc|}
\hline $\begin{array}{c}\text { Component of History } \\
\text { Taking }\end{array}$ & $\begin{array}{c}\text { Pre-Test } \\
\text { Median } \\
(\text { Mean) }\end{array}$ & $\begin{array}{c}\text { Post-Test } \\
\text { Median } \\
\text { (Mean) }\end{array}$ & Z value & $\begin{array}{c}\text { Significance } \\
\text { ( 2 tailed) }\end{array}$ \\
\hline Socio-demography & $2(2.24)$ & $3(2.78)$ & $-3.986^{\mathrm{a}}$ & .000 \\
\hline c/o according to patient & $1(1.27)$ & $3(2.69)$ & $-5.706^{\mathrm{a}}$ & .000 \\
\hline c/o according to relative & $1(1.33)$ & $3(2.64)$ & $-5.844^{\mathrm{a}}$ & .000 \\
\hline ODP & $1(1.38)$ & $3(2.60)$ & $-5.907^{\mathrm{a}}$ & .000 \\
\hline Negative History & $1(1.24)$ & $2(1.62)$ & $-3.710^{\mathrm{a}}$ & .000 \\
\hline Past History & $2(1.80)$ & $3(2.51)$ & $-4.641^{\mathrm{a}}$ & .000 \\
\hline Family History & $2(1.98)$ & $3(2.89)$ & $-5.586^{\mathrm{a}}$ & .000 \\
\hline Personal History & $1(1.40)$ & $3(2.78)$ & $-5.755^{\mathrm{a}}$ & .000 \\
\hline General Examination & $2(1.96)$ & $3(2.89)$ & $-5.514^{\mathrm{a}}$ & .000 \\
\hline MSE & $1(1.16)$ & $2(1.56)$ & $-4.025^{\mathrm{a}}$ & .000 \\
\hline
\end{tabular}

Wilcoxon signed rank test to compare median ( $\mathrm{a}=$ Based on negative ranks) 
As per figure 1 and table 2; Checklist of history taking of Major Depressive Disorder (MDD) patients has higher median score in post-test than in pre-test in all components of history taking. Interns had poor skills of taking history in asking complaints to the patient and relatives, Origin, Duration and Progress (ODP) of illness, Negative history and MSE. These all skills improved post-test up to excellent level, which indicates that teaching history taking of MDD during 2 weeks term was very useful.

\section{Evaluation by SMCQ Score:}

Total 15 SMCQs related to MDD and history taking was asked on Day 1 and Day 15. Mean score of SMCQ test was higher post-test (Mean $=12 \pm 0.83,80 \%$ result) than pre-test (Mean $=6 \pm 0.83,40 \%$ result). This suggests that Interns knowledge improved twice in their term posting.

\section{Feedback by Interns:}

Figure 2: Feedback by Interns

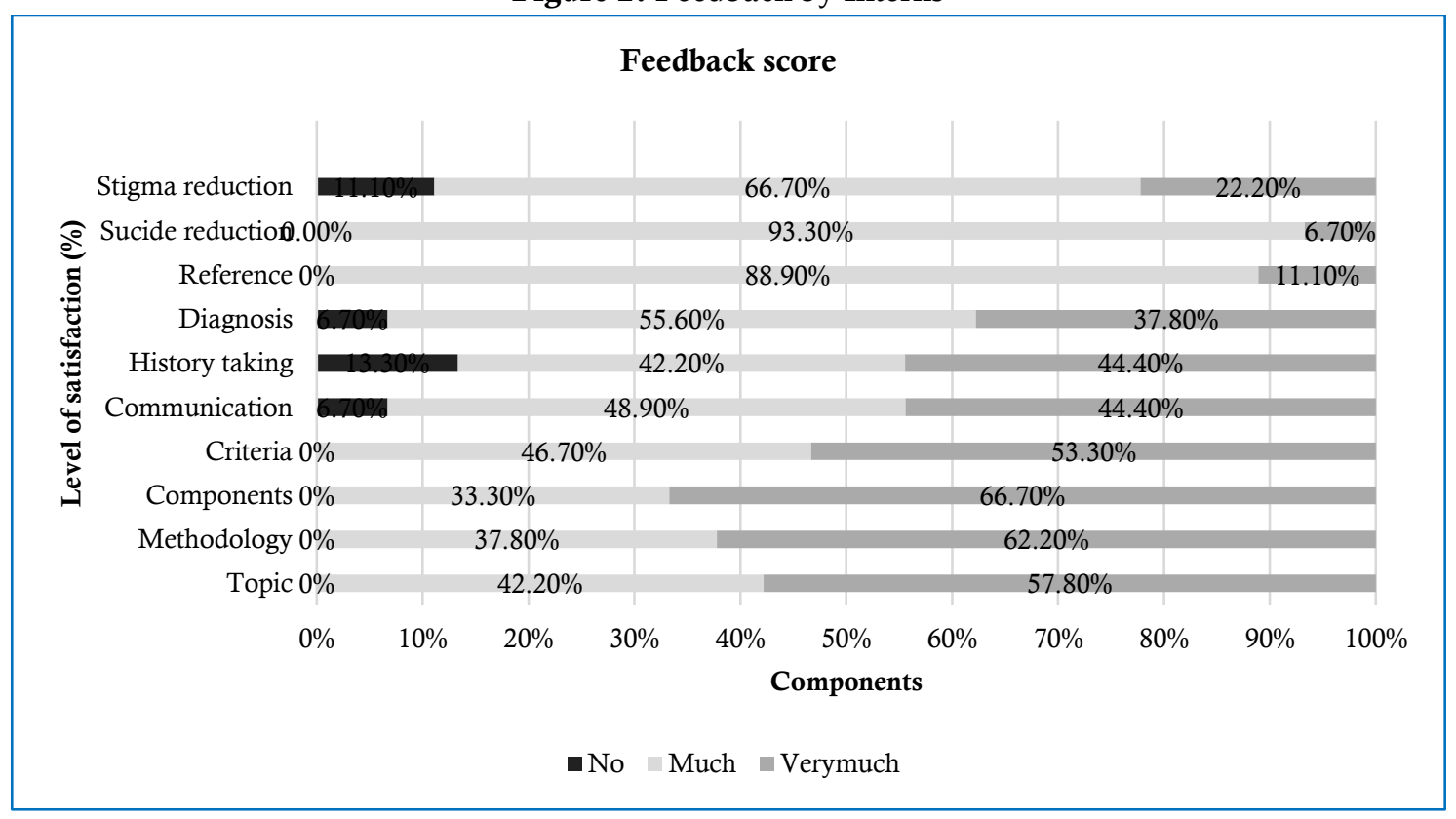

As per figure 2, Majority (around 90\%) interns reported that awareness by such teaching can reduce stigma toward psychiatric illness.

All interns gave feedback that they are sure that treating patients of MDD can reduce rate of suicide and they will refer patient to psychiatrist so that treatment can be started early. This is very encouraging statement. Around half of the interns (60\%) were very much satisfied with topic \& methodology of the study, learned components of history taking and all interns learnt criteria of MDD. More than $90 \%$ of Interns said that now they can diagnose patients with MDD and more than $85 \%$ reported that they can take history of MDD now. Around $95 \%$ of Interns were confident that their communication style with patients improved significantly.

\section{Evaluation by Mini-CEX:}

As per figure 4 and table 3 , interns had unsatisfactory skills $(1,2,3)$ of medical interview, professionalism, clinical judgment, counseling skill and organization whereas satisfactory level of physical examination skill and overall clinical competence in pre-test evaluation.

On post-test evaluation, components like medical interview skill, physical examination skill, professionalism an organization skill had increased score up to superior level $(7,8,9)$ whereas clinical judgment, counselling skill, clinical competence, satisfaction of evaluator and interns had increased score up to satisfactory level $(4,5,6)$ 
Figure 3: Mini-CEX findings

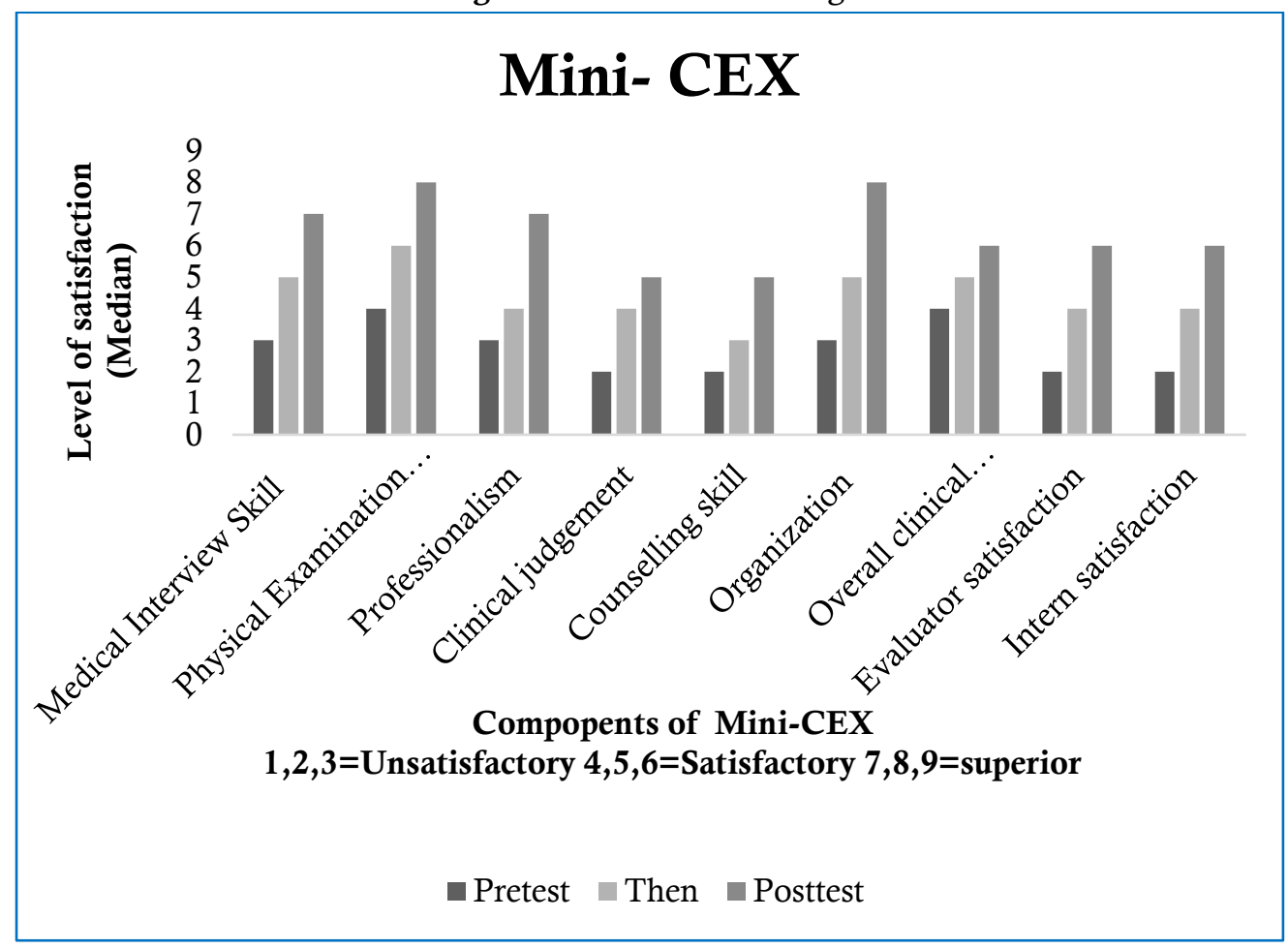

Table 3: Mini-CEX Score

\begin{tabular}{|c|c|c|c|c|c|}
\hline No & Question & $\begin{array}{l}\text { Pre-Test } \\
\text { (Day } 1)^{*}\end{array}$ & $\begin{array}{c}\text { Mid } \\
\text { Evaluation } \\
(\text { Day } 7)^{*}\end{array}$ & $\begin{array}{l}\text { Post-Test } \\
\text { (Day } 15)^{*}\end{array}$ & $\begin{array}{c}\chi^{2} \\
\text { (P Value) }\end{array}$ \\
\hline 1 & Medical Interview Skills & 3 & 5 & 7 & $\begin{array}{c}86.58 \\
(0.000)\end{array}$ \\
\hline 2 & Physical Examination Skills & 4 & 6 & 8 & $\begin{array}{c}85.72 \\
(0.000)\end{array}$ \\
\hline 3 & $\begin{array}{c}\text { Humanistic } \\
\text { Qualities/Professionalism }\end{array}$ & 3 & 4 & 7 & $\begin{array}{c}84.57 \\
(0.000)\end{array}$ \\
\hline 4 & Clinical Judgment & 2 & 4 & 5 & $\begin{array}{c}84.72 \\
(0.000)\end{array}$ \\
\hline 5 & Counselling Skills & 2 & 3 & 5 & $\begin{array}{c}80.83 \\
(0.000)\end{array}$ \\
\hline 6 & Organization/Efficiency & 3 & 5 & 8 & $\begin{array}{l}88.58 \\
(0.000)\end{array}$ \\
\hline 7 & Overall Clinical Competence & 4 & 5 & 6 & $\begin{array}{c}83.00 \\
(0.000)\end{array}$ \\
\hline 8 & $\begin{array}{l}\text { Evaluator Satisfaction with Mini- } \\
\text { CEX }\end{array}$ & 2 & 4 & 6 & $\begin{array}{c}85.51 \\
(0.000)\end{array}$ \\
\hline 9 & Intern Satisfaction with Mini-CEX & 2 & 4 & 6 & $\begin{array}{c}87.31 \\
(0.000)\end{array}$ \\
\hline
\end{tabular}

By Friedman Test, * is Median Score

Qualitative Feedback: 
a. Qualitative feedbacks from Interns:

- I have never learnt taking history of any psychiatric disorder in such a systematic \& detailed way

- I will never forget taking history of MDD patient because of such a nice personalized experience

- If I will refer MDD patient to a psychiatrist \& he will improve, it will be a most satisfactory thing to me

\section{b. Qualitative feedbacks from Faculties:}

- It was a very satisfactory \& novel experience of teaching \& evaluating case history to interns

- If at least $50 \%$ of interns have properly learnt taking history of MDD, I will consider this as a success of this project

- I have used MINI CEX for the 1st time to evaluate students \& found it easy, useful \& reliable tool for evaluation

- By conducting such projects not only interns get knowledge regarding common

- If such studies are done for all common psychiatric disorders it will go a long way to reduce stigma of psychiatric disorders

- It has motivated me also to take such projects in U.G.s \& interns in future

\section{DISCUSSION}

From 2008, 2 weeks' psychiatry posting is compulsory during internship. Formal teaching during internship is not feasible given the time constraints in most departments, but having a guideline about what the posting should achieve for the intern and the department will be beneficial to both. As such every intern should work up cases of depression, anxiety, psychosis, other mood disorders, delirium, substance dependence, consultation liaison psychiatry cases to identify abnormal illness behaviour and psychiatric aspects of physical illnesses. This should be both in inpatients and in outpatients. The number of cases to be worked up depends on the availability of patients in the department and the faculty required for supervision. They have to demonstrate skills to take psychiatric history, to do a mental state examination and counsel patients [42].

We focused on teaching proper history taking of MDD only so that Interns at least learn what the components of history taking of MDD are and how psychiatry history can be taken. The primary objective as mentioned is to equip the interns to practice psychiatry at the primary care level. So as an initiative, we taught them the most basic and essential part of psychiatry which is history taking in the patients of MDD which is very common among general population. Before teaching history taking in the study; while on taking history of MDD patients on Day 1, students found socio-demographic details, past and family history and general examination components of history taking easier than other components of history taking like how to ask chief complaints, ODP of illness, negative history and MSE. After teaching, other components of history taking also became easier on Day 15 which indicates that session of teaching acted as a learning tool evoking previous knowledge acquired during MBBS and helped to reconstruct knowledge, skills and attitude [60-62]. The reason why interns found socio-demographic details, past and family history and general examination easier than other components may be that they have learnt history taking during their clinical terms in other departments which are similar in history of psychiatric patients and other patients.

In our study overall results of SMCQ on pre-test was $40 \%$ with mean score of $6 \pm 0.83$ which increased to $80 \%$ with mean score of $12 \pm 0.83$ after teaching MDD. This study is supported by Kumar AT et al in which test scores in paediatric patients before and after teaching had statistically significant difference. [58] This is contradictory to result a study [61] in which there is no effect of teaching on MCQ scores among students. The reason for lesser score in pre-test may be that they might have read psychiatric disorder only for exam purpose as only 2 questions of psychiatry are asked and that is also in general medicine paper in final MBBS and giving much attention to specific things like criteria of disorder, duration of illness and clinical aspects like history taking especially MSE.

Results of Mini- clinical evaluation exercise (Mini-CEX) in our study suggest that there was statistically significant difference in level of satisfaction regarding various components of Mini-CEX pre-test and posttest. So, Mini-CEX was found to be useful tool for assessment of impact of education among medical students. In another study, undergraduate students have found Mini-CEX as feasible and satisfactory tool 
[61]. A systematic review and meta-analysis done also suggested positive effect of Mini-CEX application on trainee's performance [64].

One third of students were satisfied of learning medical interview skills and two third were more than satisfied with same which is similar to results of a study in which $96 \%$ students were satisfied with communicative skills [65]. There are many studies indicating positive effects of teaching on communication skills [66-68]. 94\% students in our study were much satisfied with their diagnosing ability of M.D.D. after learning history taking of M.D.D. which is similar to that seen in previous studies [63]. 89\% students agreed that their attitude towards psychiatry has been changed which is similar to study done previously [69].

In our study almost all students were much sure treating patients of M.D.D. can reduce rate of suicide which has been studied by authors that education and teaching reduced suicidal rate by $60 \%$ [70]. Qualitative feedback by both interns and faculties were positive and encouraging which was similar to the studies done in the past [71-72].

\section{CONCLUSION}

From this study, conclusions that were reached:

Teaching history taking improved interns,

- Art of detailed history taking

- Communication skills

- Diagnostic competency

- Attitude (stigma) toward Psychiatry

\section{Limitations}

$>$ We taught only history taking and one disorder that was M.D.D. due to time limitation of only 15 days for compulsory internship Psychiatry posting.

$>$ During internship also, students have NEET PG classes and for that they take leaves so they can't concentrate properly in clinical term.

\section{Recommendations}

- To learn proper history taking skills, to know basic and common psychiatric disorders, to master the communication skills, to learn a good doctor-patient relationship and to decrease stigma towards Psychiatry all undergraduate students and Interns should be compulsorily posted in psychiatry.

- All medical students should receive compulsory clinical posting in Psychiatry department in second year and in internship for optimum period (Minimum 1 month) because communication skills will make them better doctor and it will help them in their clinical practice in future.

- The training should use clinically evaluable methods like Mini-CEX, OSCE and OSPE etc. and should primarily address most basic and problem defining skills of psychiatry.

- Moreover, Psychiatry should be a separate subject at undergraduate level. At present weightage of Psychiatry is so low that students are not taking interest and not taking the subject sincerely.

\section{REFERENCES}

1. Surya NC. Transaction-4. Bangalore: All India Institute of Mental Health; 1964. Mental morbidity in Pondicherry; pp. 50-61.

2. Carstairs GM, Kapur RL. London: The Hogarth Press; 1976. The great universe of Kota: Stress, change, and mental disorder in an Indian village; pp. 70-100.

3. Saxena S. Mental Health Atlas. Ch. 4.2. Geneva: WHO; 2011.

4. Thirunavukarasu M, Thirunavukarasu P. Training and National deficit of psychiatrists in India-A critical analysis. Indian J Psychiatry 2010;52:S83-8. 
5. Bridges KW, Goldberg DP. Somatic presentation of DSM III psychiatric disorders in primary care. J Psychosom Res 1985;29:563-9.

6. Goldberg D. Reasons for misdiagnosis. In: Sartorius N, de Girolamo G, Goldberg D, Costa e Silva JA, Lecrubier Y, Wittchen HU, editors. Psychological disorders in general medical settings. Göttingen: Hogrefe and Hubert; 1990. pp. 139-45.

7. Maguire GP, Julier DL, Hawton KE, Bancroft JH. Psychiatric morbidity and referral on two general medical wards. BMJ 1974;1:268-70.

8. Chawla JM, Balhara YP, Sagar R, Shivaprakash Undergraduate medical students' attitude toward psychiatry: A cross-sectional study. Indian J Psychiatry 2012;54:37-40.

9. Kelly B, Raphael B, Byrne G. The evaluation of teaching in undergraduate psychiatric education: Students' attitudes to psychiatry and the evaluation of clinical competency. Med Teach 1991;13:77-87.

10. Nichols LO, Mirvis DM. Physician-patient communication: does it matter? Tenn Med 1998;91(3):94-6.

11. Davidoff F, Deutsch S, Egan KL, Ende J. Who Has Seen A Blood Sugar? - Reflections on Medical Education. Edited by the American College of Physicians. Philadelphia: American College of Physicians; 1996.

12. Engel GE, Morgan WL. Interviewing and patient care. Philadelphia: Saunders; 1973

13. Lipkin Jr M. The medical interview and related skills. In: Branch W, editor. Office Practice of Medicine. Philadelphia: WB Saunders Co; 1987. p. 1287-306.

14. Engel GL. Enduring attributes of medicine relevant for the education of the physician. Ann Intern Med 1973;78:587-93.

15. Novack DH, Volk G, Drossman DA, Lipkin Jr M. Medical interviewing and interpersonal skills teaching in US medical schools. Progress, problems, and promise. JAMA 1993;269(16):2101-5.

16. 16. Fortin AH, Haeseler FD, Angoff N, Cariaga-Lo L, Ellman MS, Vasquez L. Teaching pre-clinical medical students an integrated approach to medical interviewing: half-day workshops using actors. J Gen Intern Med 2002;17(9):704-8.

17. Hatem DS, Barrett SV, Hewson M, Steele D, Purwono U, Smith R. Teaching the medical interview: methods and key learning issues in a faculty development course. J Gen Intern Med 2007;22(12):1718-24.

18. Novack DH, Dube C, Goldstein MG. Teaching medical interviewing. A basic course on interviewing and the physician-patient relationship. Arch Intern Med 1992;152(9):1814-20.

19. Windish DM, Price EG, Clever SL, Magaziner JL, Thomas PA. Teaching medical students the important connection between communication and clinical reasoning. J Gen Intern Med 2005;20(12):1108-13.

20. Sanson-Fisher R, Maguire P. Should skills in communicating with patients be taught in medical schools? Lancet 1980;2(8193):523-6.

21. Novack DH. Therapeutic aspects of the clinical encounter. J Gen Intern Med 1987;2(5):346-55.

22. Peterson MC, Holbrook JH, Von Hales D, Smith NL, Staker LV. Contributions of the history, physical examination, and laboratory investigation in making medical diagnoses. West J Med 1992;156(2):163-5.

23. Hampton JR, Harrison MJ, Mitchell JR, Prichard JS, Seymour C. Relative contributions of history-taking, physical examination, and laboratory investigation to diagnosis and management of medical outpatients. BMJ 1975;2(5969):486-9.

24. Kassirer JP. Teaching clinical medicine by iterative hypothesis testing. Let's preach what we practice. N Engl J Med 1983;309(15):921-3.

25. Roshan M, Rao AP. A study on relative contributions of the history, physical examination and investigations in making medical diagnosis. J Assoc Physicians India 2000;48(8):771-5.

26. Sandler $\mathrm{G}$. The importance of the history in the medical clinic and the cost of unnecessary tests. Am Heart $\mathrm{J}$ 1980;100(6):928-31.

27. Curtis-Barton MT, Eagles JM. Factors that discourage medical students from pursuing a career in psychiatry. Psychiatrist 2011;35:425-9

28. Korszun A, Dharmaindra N, Koravangattu V, Bhui K. Teaching medical students and recruitment to psychiatry: Attitudes of psychiatric clinicians, academics and trainees. Psychiatrist 2011;35:350-3

29. Yadav T, Arya K, Kataria D, Balhara YS. Impact of psychiatric education and training on attitude of medical studentstowards mentally ill: A comparative analysis. Industr Psychiatry J 2012;21:22-31.

30. Gulati P, Das S, Chavan B S. Impact of psychiatry training on attitude of medical students toward mental illness and psychiatry. Indian J Psychiatry 2014;56:271-7.

31. Investing in mental health. Geneva: WHO; 2003. World Health Organization

32. Bruhan JG, Parsons OA. Medical students' attitude towards four medical specialties. J Med Educ 1964;39:409.

33. Lingeswaran A. Psychiatric curriculum and its impact on the attitude of Indian undergraduate medical students and interns. Indian J Psychol Med 2010;32(2):119-23. 
34. Medical Council of India. Salient features of regulations on graduate medical education, 1997. Published in Part III, Section 4 of the Gazette of India dated 17 May 1997 (amended upto Nov 2010)

35. Medical Council of India. Amendment Notification. No. MCI-34 (41)/2008-Med./29527. New Delhi, Letter dated 20th October, 2008

36. Lampe L, Coulston C, Walter G, Malhi G. Familiarity breeds respect: Attitudes of medical students towards psychiatry following a clinical attachment. Australas Psychiatry 2010;18:348-53.

37. Das MP, Chandrasena RD. Medical students' attitude towards psychiatry. Can J Psychiatry 1988;33:783-7.

38. Schildmann J, Kampmann M, Schwantes U. Teaching courses on aspects of medical history taking and communication skills in Germany: a survey among students of 12 medical faculties. Z Arztl Fortbild Qualitatssich 2004;98(4):287-92.

39. Hargie O, Dickson D, Boohan M, Hughes K. A survey of communication skills training in UK schools of medicine: present practices and prospective proposals. Med Educ 1998;32(1):25-34.

40. Association of American Colleges. Learning Objectives for Medical Student Education: Guidelines for Medical Schools (MSOP Report) Washington DC: Association of American Medical Colleges; 1998.

41. General Medical Council. Tomorrow's Doctors: Recommendations on Undergraduate Medical Education. London: General Medical Council; 1991.

42. Manohari SM, Johnson PR, Galgali RB. How to teach psychiatry to medical undergraduates in India?: A model. Indian J Psychol Med 2013;35:23-8.

43. Kogan JR, Holmboe ES, Hauer KE. Tools for direct observation and assessment of clinical skills of medical trainees: a systematic review. JAMA 2009;302(12):1316-26.

44. Holmboe ES. Faculty and the observation of trainees' clinical skills: problems and opportunities. Acad Med 2004;79:16-22.

45. Fromme HB, Karani R, Downing SM. Direct observation in medical education: a review of the literature and evidence for validity. Mt Sinai J Med 2009;76:365-71.

46. Holmboe ES, Hawkins RE, Huot SJ. Effects of training in direct observation of medical residents' clinical competence: A randomized trial Ann Intern Med 2004;140:874-81.

47. Newble DI, Baxter A, Elmslie RG. A comparison of multiple-choice tests and free-response tests in examinations of clinical competence. Med Educ 1979;13:263-8.

48. Newble D. Techniques for measuring clinical competence: Objective structured clinical examinations. Med Educ 2004;38:199-203.

49. Norcini JJ, Blank LL, Arnold GK, Kimball HR. The mini-CEX (clinical evaluation exercise): a preliminary investigation. Ann Intern Med 1995;123(10):795-9.

50. Kogan JR, Bellini LM, Shea JA. Implementation of the mini-CEX to evaluate medical students' clinical skills. Acad Med 2002;77:1156-7.

51. Tokode OM, Dennick R. A qualitative study of foundation doctors' experiences with mini-CEX in the UK Int. J Med Educ 2013;4:83-92.

52. Norcini J, Burch V. Workplace-based assessment as an educational tool: AMEE Guide No. 31. Med Teach 2007;29:855-71.

53. Norcini JJ, Blank LL, Duffy FD, Fortna GS. The mini-CEX: a method for assessing clinical skills. Ann Intern Med 2003;138:476-81.

54. Meresh E, Daniels D, Sharma A, Rao M, Mehta K, Schilling D. Review of mini-clinical evaluation exercise (mini-CEX) in a psychiatry clerkship. Adv Med Educ Pract 2018;9:279-83.

55. Yager J. Specific components of bedside manner in the general hospital psychiatric consultation: 12 concrete suggestions. Psychosomatics 1989;30(2):209-12.

56. The Medical Council of India [Internet] India: Faculty Development Programmes; [updated 2015 May 6; cited 2015 May 8]. Available http://www.mciindia.org/InformationDesk/ForColleges/FacultyDevelopmentProgrammes.aspx

57. Zodpey S, Sharma A, Zahiruddin QS, Gaidhane A, Shrikhande S. Faculty development programs for medical teachers in India. J Adv Med Educ Prof 2016;4(2):97-101.

58. Torre DM, Simpson DE, Elnicki DM, Sebastian JL, Holmboe ES. Feasibility, reliability and user satisfaction with a PDA-based mini-CEX to evaluate the clinical skills of third-year medical students. Teach Learn Med 2007;19(3):271-7.

59. Mortaz Hejri S, Jalili M, Shirazi M, Masoomi R, Nedjat S, Norcini J. The utility of mini-Clinical Evaluation Exercise (mini-CEX) in undergraduate and postgraduate medical education: protocol for a systematic review. Syst Rev 2017;6:146.

60. Kumar A, Sangeeta A, Rashmi R, Jyothi S, Aravazhi AN. Formative assessment and documentation of history taking in pediatrics: a comparative study. Int J Contempor Pediatr 2018;5(2):621-8. 
61. Junger J, Schafer S, Roth C, Schellberg D, Friedman Ben- David M, Nikendei C. Effects of basic clinical skills training on objective structured clinical examination performance. Med Educ 2005;39(10):1015-20

62. Evans BJ, Stanley RO, Burrows GD, Sweet B. Lectures and skills workshops as teaching formats in a historytaking skills course for medical students. Med Educ 1989;23(4):364-70.

63. Hoseini BL, Jafarnejad F, Mazloum SR, Foroughipour M. Practical experience of the mini-cex in undergraduate trainees. Proc Soc Behav Sci 2013;83:803-7

64. Lorwald AC, Lahner FM, Nouns ZM, Berendonk C, Norcini J, Greif R, Huwendiek S. The educational impact of Mini-Clinical Evaluation Exercise (Mini-CEX) and Direct Observation of Procedural Skills (DOPS) and its association with implementation: A systematic review and meta-analysis. PloS One 2018;13(6): $\mathrm{e} 0198009$

65. Sukhlecha A, Dass R, Tiwari DS, Anand NI, Dholakia HJ. Structured communicative skills training for medical interns improves history taking skills on sensitive issues: An interventional study. Med J DY Patil Univ 2016;9(5):579-85.

66. Ramasamy R, Murugaiyan SB, Rachel S, Vengadapathy KV, Gopal N. Communication skills for medical students: An overview. J Contemp Med Educ 2014;2:134-40.

67. Jorwekar GJ, Apturkar DK, Baviskar PK, Shaikh MH. Training of intern doctors with interpersonal communication [IPC]: A step towards better doctor patient relationship. Int J Biomed Adv Res 2015;6:422-6.

68. Hausberg MC, Hergert A, Kröger C, Bullinger M, Rose M, Andreas S. Enhancing medical students' communication skills: Development and evaluation of an undergraduate training program. BMC Med Educ 2012;12:16

69. Singh SP, Baxter H, Standen P, Duggan C. Changing the attitudes of tomorrow's doctors' towards mental illness and psychiatry: a comparison of two teaching methods. Med Educ 1998;32(2):115-20.

70. Rutz W. Preventing suicide and premature death by education and treatment. J Affect Disord 2001;62(12):123-9.

71. Keifenheim KE, Teufel M, Ip J, Speiser N, Leehr EJ, Zipfel S, Herrmann-Werner A. Teaching history taking to medical students: a systematic review. BMC Med Educ 2015;15(1):159.

72. Tekian A, Watling CJ, Roberts TE, Steinert Y, Norcini J. Qualitative and quantitative feedback in the context of competency-based education. Med Teach 2017;39(12):1245-9.

$* * * * * * * * * * * * * * * * * * * * * * * * * * * * * * * * * * * *$

Acknowledgements - All faculties of MCI Nodal Centre for Medical Education, Smt. NHL Municipal Medical College, Ahmedabad; All faculties and P.G. students of Dept. of Psychiatry; Dr. Mayank Patel, Assistant Professor (P.S.M. / Community Medicine) dept. of AMC MET Medical College, Ahmedabad

Conflict of Interest - Nil

Funding - Nil 